\title{
Immunoregulatory Potential of Exosomes Derived from Cancer Stem Cells
}

\author{
Shannon M. Clayton, ${ }^{1}$ Joehleen A. Archard, ${ }^{1}$ Joseph Wagner, ${ }^{2}$ D. Gregory Farwell, ${ }^{1}$ \\ Arnaud F. Bewley, ${ }^{1}$ Angela Beliveau, ${ }^{1}$ Andrew Birkeland, ${ }^{1}$ Shyam Rao, Marianne Abouyared, \\ Peter C. Belafsky, and Johnathon D. Anderson ${ }^{1}$
}

Head and neck squamous cell carcinomas (HNSCCs) are malignancies that originate in the mucosal lining of the upper aerodigestive tract. Despite advances in therapeutic interventions, survival rates among HNSCC patients have remained static for years. Cancer stem cells (CSCs) are tumor-initiating cells that are highly resistant to treatment, and are hypothesized to contribute to a significant fraction of tumor recurrences. Consequently, further investigations of how CSCs mediate recurrence may provide insights into novel druggable targets. A key element of recurrence involves the tumor's ability to evade immunosurveillance. Recent published reports suggest that CSCs possess immunosuppressive properties, however, the underlying mechanism have yet to be fully elucidated. To date, most groups have focused on the role of CSC-derived secretory proteins, such as cytokines and growth factors. Here, we review the established immunoregulatory role of exosomes derived from mixed tumor cell populations, and propose further study of CSC-derived exosomes may be warranted. Such studies may yield novel insights into new druggable targets, or lay the foundation for future exosome-based diagnostics.

Keywords: cancer stem cells, exosomes, regulatory $\mathrm{T}$ lymphocytes, $\mathrm{m} 2$ macrophages, head and neck cancer, secretory proteins

\section{Introduction}

$\mathrm{H}$ EAD AND NECK squamous cell carcinoma (HNSCC) is the sixth most common type of cancer, with $\sim 500,000$ new cases each year worldwide [1,2]. Over $70 \%$ of head and neck cancers are associated with alcohol and tobacco consumption $[3,4]$. HNSCC early-stage treatment typically includes surgery or radiotherapy while advancestages frequently employ a combination of surgery followed by chemoradiotherapy [5,6]. Patient survival rates are often low as a result of local and regional recurrence, with a $40 \%$ mortality within 5 years post-treatment in highrisk patients [7-10].

Immunosurveillance and immunoediting play an integral role in the progression and recurrence of HNSCC tumors $[11,12]$. The development of murine tumor models with molecularly defined immunodeficiencies has enabled the field to demonstrate the existence of cancer immunosurveillance processes that are capable of preventing tumor progression $[13,14]$. A large body of work has established that the immune system can select for the emergence of tumors with limited immunogenicity, capable of escaping immune recognition and elimination [15-17]. This work led to the development of the cancer immunoediting hypothesis that determines the potential host-protective and tumor-sculpting properties of the immune system during tumor development $[18,19]$.

The immune system recognizes tumors through the expression of tumor-associated antigens (TAA) [20,21]. TAAs are phagocytozed by professional antigen-presenting cells (APCs), such as macrophages and dendritic cells (DCs) $[22,23]$. APCs then present TAA on major histocompatibility complex (MHC)-II complexes, which subsequently interact with $\mathrm{T}$ cell receptors, thereby inducing an activation signaling cascade that results in the cytotoxic elimination of TAA bearing tumor cells $[15,24]$.

Progressive tumors may evade and impair the immune system through the release of a variety of factors, creating a hypoimmunogenic tumor microenvironment $[25,26]$. The secretion of cytokines with anti-inflammatory properties such as transforming growth factor beta (TGF $\beta$ ) and interleukin (IL)-10 can lead to the suppression of immune cells involved in antitumor immunity, such as CD8+ T cytotoxic cells and DCs [27-35]. These cytokines can also induce immune cells with immunosuppressive properties such as

\footnotetext{
${ }^{1}$ Department of Otolaryngology, University of California, Davis, Sacramento, California.

${ }^{2}$ University of California Drug Discovery Consortium, University of California, Davis, Sacramento, California.
} 
regulatory $\mathrm{T}$ lymphocytes (Tregs) and myeloid derived suppressor cells (MDSCs), which permit tumors to evade immunosurveillance and elimination [36-43].

In recent years, several groups have leveraged this increased understanding of the immunobiology underlying tumor development and immunoediting to develop novel targeted immunotherapeutic strategies to reactivate the immune system [44-46]. The development of antagonist antibodies against immune checkpoint pathways have led to several successful drug approvals and effective implementation into clinical practice [47-49].

Antibody inhibitors of the PD-1/PD-L1 axis is one such therapeutic approach that has achieved remarkable success in a subset of patients [50,51]. In addition, several novel immunotherapies developed from genetically modified chimeric antigen receptor $\mathrm{T}$ cells (CAR $\mathrm{T}$ cells), have shown significant promise in targeting hematological malignancies, such as certain subtypes of leukemia and lymphoma [52,53]. However, the application of CAR T cell technology to solid tumors remains challenging [54-57]. Epidermal growth factor receptor (EGFR) has been identified as a potential target in epithelial tumors, such as HNSCC [58,59]. This has led to the development of EGFR targeting CAR T cells in non-small cell lung cancer that have undergone early stage clinical trials and has been determined to be safe $[60,61]$. Further elucidation of the mechanisms by which tumors develop equilibrium and eventually escape immunosurveillance is critical to develop additional novel therapeutic approaches and diagnostics [62,63].

\section{Tumor-derived exosomes}

To date, most reports investigating immunoediting by tumors has focused on canonical secretory factors, such as growth factors and cytokines [64,65]. However, there is a growing body of evidence that suggests that intercellular communication between tumor cells and stroma and immune cells also occurs through tumor-derived extracellular vesicles called exosomes (TEX) [66-69]. Exosomes are cellularly secreted lipid bilayer nanovesicles secreted by virtually all cells [70,71]. Exosomes function as a robust and intricate intercellular communication system, which is evolutionarily conserved down to gram negative bacteria [72,73]. TEX transmit malignant information in the form of proteins, RNAs, lipids, and metabolites that can reprogram recipient cells $[74,75]$.

There has been a growing body of work indicating that TEX isolated from the plasma of cancer patients may hold value as diagnostic and prognostic biomarkers, as a "liquid biopsy" of the tumor [76-78]. Exosomes' contents and concentration in the plasma of patients with HNSCC has allowed for the differentiation between patients with active disease, no evident disease, and between early/advanced stages of tumor progression $[79,80]$. These findings highlight the potential use of TEX diagnostic biomarkers for HNSCC $[81,82]$. Indeed, such TEX-based biomarkers as liquid biopsy diagnostics from Exosome Diagnostics were recently approved for clinical use for prostate and lung cancer $[83,84]$. These diagnostics aid clinicians in detecting, diagnosing, and monitoring cancer progression in addition to identifying the unique genetic composition of each patient's tumor.

Several groups have also established that TEX functionally mediate cancer progression via facilitating tumor growth and promotion of the tumor microenvironment through localized suppression of immune surveillance through a variety of reported mechanisms [85-87]. APCs, such as macrophages and DCs, phagocytose TEX, initiating signaling cascades that ultimately induce a regulatory phenotype among professional APCs $[88,89]$. Ligands on the surface of TEX can also bind cognate receptors on a cell's surface, inducing specific pathway signaling activation, which can also result in receptor-mediated endocytosis, releasing the contents of TEX within the target cell populations [90,91]. Alternatively, TEX ligands can bind cell surface receptors, like MHC-I on lymphocytes, triggering suppressive signaling pathways without entering the cell $[92,93]$. Further, PD-L1 expression on TEX has been demonstrated to suppress antitumor immunity and memory, and it may potentially account for limited response rates of current therapeutic antibody approaches [94].

TEX can also suppress the immune system indirectly through ectoenzymes CD39 and CD73 bound to the surface of TEX. CD39 hydrolyzes ATP into 5' AMP and CD73 hydrolyzes 5' AMP into adenosine [95,96]. Adenosine signals through the $\mathrm{A} 2 \mathrm{AR}$ and $\mathrm{A} 2 \mathrm{BR}$ receptors on tumorassociated macrophages (TAMs), MDSCs, natural killer cells, Tregs, DCs, and cytotoxic CD8+ T cells in a paracrine fashion (Fig. 1) [97-100]. HNSCC-derived TEX have also been shown to induce apoptosis of CD8+ cytotoxic T cells $[101,102]$. CD95 and PD-1 receptors on the surface of CD8+

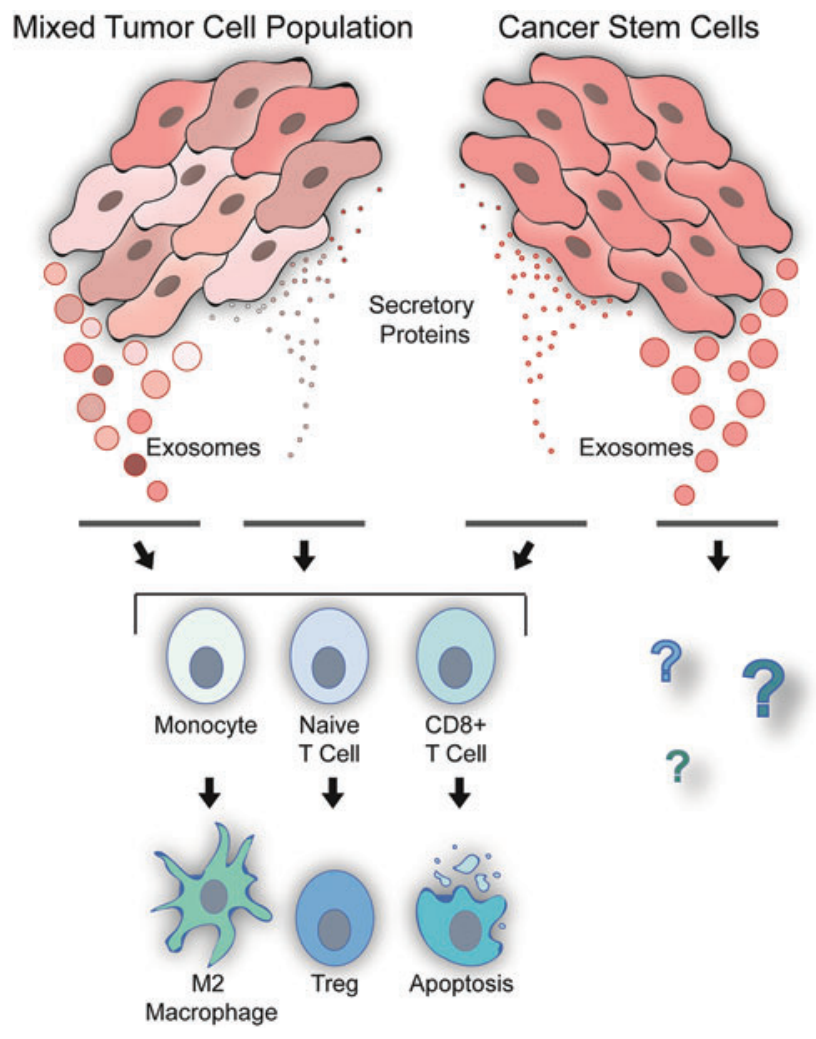

FIG. 1. Exosomes derived from mixed tumor cell populations possess potent immunoregulatory properties, including, M2 macrophage polarization, Treg induction, and elimination of CD8+ cytotoxic T cells. CSCs have been shown to have immunomodulatory properties, yet it is currently not clear if CSC derived exosomes mediate these properties. CSCs, cancer stem cells. Treg, regulatory $\mathrm{T}$ lymphocyte. Color images are available online. 
T cells are bound by TEX surface molecules FasL and PD-L1, respectively, inducing apoptosis [103,104]. Additionally, excess levels of PD-L1+ exosomes detected in patient plasma were associated with advanced HNSCC disease [104]. TAMs are highly abundant in the tumor microenvironment and have been established to promote tumor progression via facilitating immune escape $[105,106]$. Recently, miR-21+ exosomes from SNAIL+ cancer cells have been demonstrated to polarize macrophages to the M2 phenotype by targeting PDCD4 and IL-12A [107]. These studies demonstrate that TEX are capable of creating an immunosuppressive microenvironment via elimination of CD8+ cytotoxic T cells and differentiation of TAMs toward an $\mathrm{M} 2$ regulatory phenotype.

Tregs are vital for maintaining tolerance, thwarting autoimmunity, and restraining chronic inflammatory diseases [108-113]. However, Tregs also limit beneficial responses through the suppression of antitumor immunity $[114,115]$. Tregs possess several mechanisms at their disposal to mediate their immunosuppressive effects, including suppression by cytolysis, suppression by metabolic disruption, suppression by inhibitory cytokines, and suppression by the modulation of DC maturation or function [116,117].

Elevated levels of Tregs have been observed in multiple tumor types [118]. Tregs and conventional CD4+ T cells are recruited to the tumor microenvironment via CCL20 of TEX [119]. TEX induce CD4+CD25- T cells into CD4+CD25+FOXP3+ Tregs in a TGF $\beta$ and IL-10dependent manner, which results in phosphorylation and activation of the Smad2/3 and STAT3 signaling factors [120]. TEX also induce the upregulation of several immunosuppressive genes COX2, IL-10, CD39, CD73, PD-L1, and CD26 in Tregs [121]. The subsequent secretion of TGF $\beta$ and IL-10 by Tregs suppresses the proliferation of antitumor $\mathrm{T}$ cells via modulation of DC function and maturation [122]. Tregs also secrete cytolysis via secretion of granzyme A, granzyme B, and perforin targeting cells responsible for immunosurveillance $[123,124]$.

\section{Cancer stem cells}

Solid tumors are heterogeneous mixtures of different cellular subpopulations, which possess multiple phenotypes, differentiation, and mitogenic potentials [125-127]. A small subpopulation of tumor cells have been demonstrated to increase tumorigenicity, with stem cell-like abilities to self-renew and differentiate, which have become known as cancer stem cells (CSCs) $[128,129]$. CSCs have been attributed to resistance seen against cancer therapies, surviving both chemo and radiotherapy treatment and giving rise to local or distal recurrence in patients (Fig. 2) [130,131]. Current cancer therapeutic interventions such as surgery, radiotherapy, and chemotherapy eliminate most tumor cells, yet residual therapyresistant CSCs may account for recurrence [131-133].

Al-Hajj et al. demonstrated that a population of tumor cells in breast cancer had the ability to self-renew and differentiate, and identified cell markers for CSCs, CD44+CD24[128]. When CD44+CD24- CSCs were injected into mice, tumors formed that were phenotypically diverse and resembled the heterogeneous nature of the tumor the CSCs originated from [128]. The CD44- cells were not tumorigenic, cementing CD44 as an important marker for the

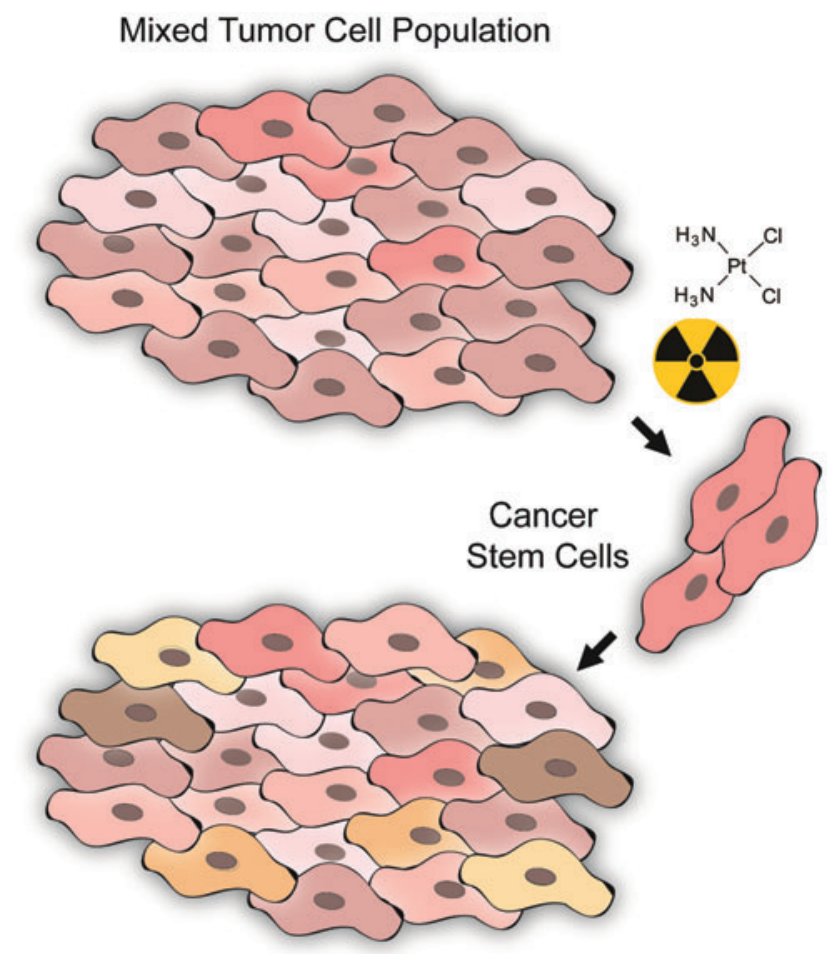

Tumor Recurrence

FIG. 2. CSCs have been reported to possess chemoradiotherapy resistance properties that result in tumor recurrence. The determination of the mechanisms by which CSCs escape canonical therapeutic interventions, and subsequent evasion of immunosurveillance may provide insights into novel druggable targets designed to limit tumor recurrence. Color images are available online.

identification of CSCs [129]. Similarly, CSCs were identified using these markers in HNSCC with similar results [134]. Populations of CD133+ cells have also been demonstrated to increase tumorigenesis, in a fashion similar to that of CD44+ cells [135]. Studies of CSC surface markers have shown CD44+ cell populations to more highly co-express CD133 than the CD44- cell population $[133,136]$. ALDH-1 was identified as an additional CSC marker, where CD44+CD24ALDH-1+ cells displayed higher potential to form tumors and possessed increased radioresistance [137].

CSCs are essential for the recurrence, and several reports have established that they protect the developing tumor from immunosurveillance and elimination by promoting a protumor microenvironment and by regulating the immune system. Recently, Miao et al. established that adaptive immune resistance emerges from CSCs [126]. CSCs demonstrate stronger inhibition of CD8+ T cells and induction of Tregs and MDSCs than non-CSC tumor cell subpopulations [138]. Several reports have established that CSCs downregulate the presentation of MHC antigens, contributing to escape from CD8+ cytotoxic T lymphocytes [139]. CSCs have also been demonstrated to polarize TAMs toward the regulatory M2 phenotype [140].

To date, most published reports of the mechanisms underlying CSCs' immunosuppressive properties have focused on their secretion of various cytokines including TGF $\beta-1$, and IL-6 [135,141,142]. These immunoregulatory cytokines 
possess potent anti-inflammatory properties, mediated by Tregs and MDSCs, which subsequently secrete additional cytokines with additional immunomodulatory properties that suppress the immune system, promoting a tumor permissive microenvironment.

CSCs are tumor-initiating cells whose progeny generate the bulk of subsequent tumor tissue. A growing body of work has established that exosomes derived from bulk tumor tissue are key mediators of communication within the tumor microenvironment, and induce protumorigenic effects in immune cells, and other nontumor bystander cells [143-145].

To date, few published reports have investigated the physiology and functional properties of CSC secreted exosomes (CSCEX) [146-148]. However, it is feasible that CSC secrete CSCEX, which possess similar immunosuppressive properties similar to TEX [85]. Numerous reports have established that exosomes derived from other stem cell source possess comparable properties as well [149-152].

The determination of whether CSCEX allow for CSC to evade immunosurveillance and facilitate relapse within an immune-permissive tumor microenvironment represents a current critical gap in knowledge that warrants further investigation [153]. Better understanding of the molecular mechanisms by which CSCEX potentially regulate antitumor immunity may yield vital insights into tumor progression, and elucidate novel drug targets for aggressive tumors [66]. Such investigations may also yield insights into novel diagnostic biomarkers that are able to discern CSC-load post-treatment using CSCEX isolated from liquid biopsies. Taken together, there is strong evidence to suggest that further study of CSCEX may yield valuable biomedical and translational insights into recurrent tumor progression.

\section{Conclusion}

CSCs are highly tumorigenic and resistant to traditional cancer treatments, giving rise to local and distal tumor recurrence. To date, published reports have focused on CSCs' secretions of cytokines rather than exosomes. However, a growing body of evidence has established that exosomes derived from complex tumor tissue specimens comprised of multiple subpopulations of cells possess potent immunoregulatory properties that facilitate tumor progression. It is critical to distinguish whether these exosomes were derived from CSCs or solely from non-CSC to identify potential mechanistic differences for novel therapeutic interventions and diagnostics specifically targeting CSCs. However, it is feasible that many of the properties attributed to TEX are also associated with CSCEX. Further investigation of CSCEX, and their effects on the immune system, may uncover previously undiscovered mechanisms underlying the suppression of antitumor immunity, thereby elucidating novel druggable immunotherapy targets. Targeting of CSCs is an attractive approach to limit cancer treatment resistance, and to prevent tumor relapse.

\section{Disclaimer}

The content is solely the responsibility of the authors and does not necessarily represent the official views of the NIH.

\section{Author Disclosure Statement}

No competing financial interests exist.

\section{Funding Information}

Authors are supported by the National Center for Advancing Translational Sciences, National Institutes of Health through grant number UL1 TR001860 and linked award KL2 TR001859. As well as, CIRM EDUC2-08390, the UC Office of the President's Multi-campus Research Program Grant (MRP-17-454909), STAIR Grant, STAIR-Plus Grant, CTSC Rapid Translational Grant (UL1-TR001860), T32 Cardio NIH T32-HL086350, Denny and Jeanene Dickenson Fellowship, NIH Transformative R01GM099688, NIH T32GM008799.

\section{References}

1. Torre LA, F Bray, RL Siegel, J Ferlay, J Lortet-Tieulent and A Jemal. (2015). Global cancer statistics, 2012. CA Cancer J Clin 65:87-108.

2. Economopoulou P, I Kotsantis and A Psyrri. (2016). The promise of immunotherapy in head and neck squamous cell carcinoma: combinatorial immunotherapy approaches. ESMO Open 1:e000122.

3. Blot WJ, JK McLaughlin, DM Winn, DF Austin, RS Greenberg, S Preston-Martin, L Bernstein, JB Schoenberg, A Stemhagen and JF Fraumeni. (1988). Smoking and drinking in relation to oral and pharyngeal cancer. Cancer Res 48:3282-3287.

4. Leemans CR, BJM Braakhuis and RH Brakenhoff. (2010). The molecular biology of head and neck cancer. Nat Rev Cancer 11:9.

5. Marur S, AA. Forastiere. (2016). Head and Neck Squamous Cell Carcinoma: Update on Epidemiology, Diagnosis, and Treatment. Mayo Clinic Proceedings 91:386396.

6. Kobayashi K, K Hisamatsu, N Suzui, A Hara, H Tomita and T Miyazaki. (2018). A review of HPV-related head and neck cancer. J Clin Med 7:241.

7. Sacco AG and EE Cohen. (2015). Current treatment options for recurrent or metastatic head and neck squamous cell carcinoma. J Clin Oncol 33:3305-3313.

8. Ferris RL, G Blumenschein, Jr., J Fayette, J Guigay, AD Colevas, L Licitra, K Harrington, S Kasper, EE Vokes, et al. (2016). Nivolumab for recurrent squamous-cell carcinoma of the head and neck. N Engl J Med 375:18561867.

9. Seiwert TY, B Burtness, R Mehra, J Weiss, R Berger, JP Eder, K Heath, T McClanahan, J Lunceford, et al. (2016). Safety and clinical activity of pembrolizumab for treatment of recurrent or metastatic squamous cell carcinoma of the head and neck (KEYNOTE-012): an open-label, multicentre, phase $1 \mathrm{~b}$ trial. Lancet Oncol 17:956-965.

10. Méry B, C Rancoule, J-B Guy, S Espenel, A-S Wozny, P Battiston-Montagne, D Ardail, M Beuve, G Alphonse and C Rodriguez-Lafrasse. (2017). Preclinical models in HNSCC: a comprehensive review. Oral Oncol 65:51-56.

11. Moskovitz JM and RL Ferris. (2018). Tumor immunology and immunotherapy for head and neck squamous cell carcinoma. J Dent Res 97:622-626.

12. Teng MWL, J Galon, W-H Fridman and MJ Smyth. (2015). From mice to humans: developments in cancer immunoediting. J Clin Invest 125:3338-3346.

13. Dunn GP, LJ Old and RD Schreiber. (2004). The three Es of cancer immunoediting. Annu Rev Immunol 22:329-360.

14. Mehra R., Seiwert T.Y., Gupta S. et al. (2018). Efficacy and safety of pembrolizumab in recurrent/metastatic head and 
neck squamous cell carcinoma: pooled analyses after longterm follow-up in KEYNOTE-012. Br J Cancer 119, 153159.

15. Economopoulou P, C Perisanidis, EI Giotakis and A Psyrri. (2016). The emerging role of immunotherapy in head and neck squamous cell carcinoma (HNSCC): antitumor immunity and clinical applications. Ann Transl Med 4:173.

16. Beatty GL and WL Gladney. (2015). Immune escape mechanisms as a guide for cancer immunotherapy. Clin Cancer Res 21:687-692.

17. Prendergast GC. (2008). Immune escape as a fundamental trait of cancer: focus on IDO. Oncogene 27:3889.

18. Dunn GP, AT Bruce, H Ikeda, LJ Old and RD Schreiber. (2002). Cancer immunoediting: from immunosurveillance to tumor escape. Nat Immunol 3:991.

19. Schreiber R, L Old and M Smyth. (2011). Cancer immunoediting: integrating immunity's roles in cancer suppression and promotion. Science (New York, NY) 331:1565.

20. Heubeck B, O Wendler, K Bumm, R Schäfer, U MüllerVogt, M Häusler, E Meese, H Iro and H Steinhart. (2013). Tumor-associated antigenic pattern in squamous cell carcinomas of the head and neck-analysed by SEREX. Eur J Cancer 49:e1-e7.

21. Zamunér FT, BTR Karia, CZ de Oliveira, CRd Santos, AL Carvalho and AL Vettore. (2015). A comprehensive expression analysis of cancer testis antigens in head and neck squamous cell carcinoma revels MAGEA3/6 as a marker for recurrence. Mol Cancer Ther 14:828-834.

22. Buonaguro L, A Petrizzo, ML Tornesello and FM Buonaguro. (2011). Translating tumor antigens into cancer vaccines. Clin Vaccine Immunol 18:23-34.

23. Krackhardt AM, M Witzens, S Harig, FS Hodi, AJ Zauls, M Chessia, P Barrett and JG Gribben. (2002). Identification of tumor-associated antigens in chronic lymphocytic leukemia by SEREX. Blood 100:2123-2131.

24. Vigneron N. (2015). Human tumor antigens and cancer immunotherapy. Biomed Res Int 2015:948501.

25. Polverini PJ, NJ D'Silva and YL Lei. (2018). Precision therapy of head and neck squamous cell carcinoma. J Dent Res 97:614-621.

26. Blankenstein T, PG Coulie, E Gilboa and EM Jaffee. (2012). The determinants of tumour immunogenicity. Nat Rev Cancer 12:307.

27. Thomas DA and J Massagué. (2005). TGF- $\beta$ directly targets cytotoxic $\mathrm{T}$ cell functions during tumor evasion of immune surveillance. Cancer Cell 8:369-380.

28. Laouar Y, T Town, D Jeng, E Tran, Y Wan, VK Kuchroo and RA Flavell. (2008). TGF- $\beta$ signaling in dendritic cells is a prerequisite for the control of autoimmune encephalomyelitis. Proc Natl Acad Sci U S A 105:10865-10870.

29. Corinti S, C Albanesi, A la Sala, S Pastore and G Girolomoni. (2001). Regulatory activity of autocrine IL-10 on dendritic cell functions. J Immunol 166:4312-4318.

30. Smith LK, GM Boukhaled, SA Condotta, S Mazouz, JJ Guthmiller, R Vijay, NS Butler, J Bruneau, NH Shoukry, CM Krawczyk and MJ Richer. (2018). Interleukin-10 directly inhibits CD8+ T cell function by enhancing $\mathrm{N}$ glycan branching to decrease antigen sensitivity. Immunity 48:299-312.e295.

31. Trandem K, J Zhao, E Fleming and S Perlman. (2011). Highly activated cytotoxic CD8 T cells express protective IL-10 at the peak of coronavirus-induced encephalitis. J Immunol 186:3642-3652.
32. Groux H, M Bigler, JE de Vries and M-G Roncarolo. (1998). Inhibitory and stimulatory effects of IL-10 on human CD8+ T cells. J Immunol 160:3188-3193.

33. Anderson JD, MT Pham, Z Contreras, M Hoon, KD Fink, HJ Johansson, J Rossignol, GL Dunbar, M Showalter, et al. (2016). Mesenchymal stem cell-based therapy for ischemic stroke. Chin Neurosurg J 2:36.

34. Deng P, JD Anderson, AS Yu, G Annett, KD Fink and JA Nolta. (2016). Engineered BDNF producing cells as a potential treatment for neurologic disease. Expert Opin Biol Ther 16:1025-1033.

35. Fink KD, P Deng, J Gutierrez, JS Anderson, A Torrest, A Komarla, S Kalomoiris, W Cary, JD Anderson, et al. (2016). Allele-specific reduction of the mutant huntingtin allele using transcription activator-like effectors in human Huntington's disease fibroblasts. Cell Transplant 25:677686.

36. Ferris RL. (2015). Immunology and immunotherapy of head and neck cancer. J Clin Oncol 33:3293-3304.

37. Mazzucchelli R, JA Hixon, R Spolski, X Chen, WQ Li, VL Hall, J Willette-Brown, AA Hurwitz, WJ Leonard and SK Durum. (2008). Development of regulatory T cells requires IL-7R $\alpha$ stimulation by IL-7 or TSLP. Blood 112: 3283-3292.

38. Vieira PL, JR Christensen, S Minaee, EJ O'Neill, FJ Barrat, A Boonstra, T Barthlott, B Stockinger, DC Wraith and A O'Garra. (2004). IL-10-secreting regulatory T cells do not express Foxp3 but have comparable regulatory function to naturally occurring $\mathrm{CD} 4+\mathrm{CD} 25+$ regulatory T cells. J Immunol 172:5986-5993.

39. Zheng SG, J Wang, P Wang, JD Gray and DA Horwitz. (2007). IL-2 is essential for TGF- $\beta$ to convert naive CD4+CD25- cells to CD25+Foxp3+ regulatory $\mathrm{T}$ cells and for expansion of these cells. J Immunol 178:20182027.

40. Wan YY and RA Flavell. (2007). 'Yin-Yang' functions of transforming growth factor- $\beta$ and $T$ regulatory cells in immune regulation. Immunol Rev 220:199-213.

41. Veglia F, M Perego and D Gabrilovich. (2018). Myeloidderived suppressor cells coming of age. Nat Immunol 19: 108-119.

42. Lee C-R, Y Kwak, T Yang, JH Han, S-H Park, MB Ye, W Lee, K-Y Sim, J-A Kang, et al. (2016). Myeloidderived suppressor cells are controlled by regulatory $\mathrm{T}$ cells via TGF- $\beta$ during murine colitis. Cell Rep 17:32193232.

43. Elahi FM, Farwell DG, Nolta JA, Anderson JD. (2020). Preclinical translation of exosomes derived from mesenchymal stem/stromal cells. Stem Cells 38:15-21.

44. Chanana R, V Noronha, A Joshi, V Patil and K Prabhash. (2018). Evolving role of immunotherapy in head-and-neck cancers: a systemic review. J Head Neck Physicians Surg 6:2-11.

45. Papa S, A Adami, M Metoudi, D Achkova, Mv Schalkwyk, AP Pereira, L Bosshard-Carter, L Whilding, Svd Stegen, et al. (2018). A phase I trial of T4 CAR T-cell immunotherapy in head and neck squamous cancer (HNSCC). J Clin Oncol 36:3046.

46. Maruse Y, S Kawano, T Jinno, R Matsubara, Y Goto, N Kaneko, T Sakamoto, Y Hashiguchi, M Moriyama, et al. (2018). Significant association of increased PD-L1 and PD-1 expression with nodal metastasis and a poor prognosis in oral squamous cell carcinoma. Int J Oral Maxillofac Surg 47:836-845. 
47. Zandberg DP, AP Algazi, A Jimeno, JS Good, J Fayette, $\mathrm{N}$ Bouganim, NE Ready, PM Clement, C Even, et al. (2019). Durvalumab for recurrent or metastatic head and neck squamous cell carcinoma: results from a single-arm, phase II study in patients with $\geq 25 \%$ tumour cell PD-L1 expression who have progressed on platinum-based chemotherapy. Eur J Cancer 107:142-152.

48. von der Grün J, F Rödel, C Brandts, E Fokas, M Guckenberger, C Rödel and P Balermpas. (2019). Targeted therapies and immune-checkpoint inhibition in head and neck squamous cell carcinoma: where do we stand today and where to go? Cancers 11:472.

49. Parameswaran J and B Burtness. (2017). Immune checkpoint inhibition in cancers that affect the head and neck. Int J Radiat Oncol Biol Phys 98:969-973.

50. Zandberg DP and SE Strome. (2014). The role of the PDL1:PD-1 pathway in squamous cell carcinoma of the head and neck. Oral Oncol 50:627-632.

51. Topalian S, C Drake and D Pardoll. (2015). Immune checkpoint blockade: a common denominator approach to cancer therapy. Cancer Cell 27:450-461.

52. Pagel JM and H West. (2017). Chimeric antigen receptor (CAR) T-cell therapy. JAMA Oncol 3:1595-1601.

53. Budde LE and JA Zaia. (2018). CD19 CAR-T therapy and sepsis: dancing with the devil. Blood 131:7-8.

54. Yu S, A Li, Q Liu, T Li, X Yuan, X Han and K Wu. (2017). Chimeric antigen receptor T cells: a novel therapy for solid tumors. J Hematol Oncol 10:78.

55. Martinez M and EK Moon. (2019). CAR T cells for solid tumors: new strategies for finding, infiltrating, and surviving in the tumor microenvironment. Front Immunol 10:128.

56. Brown MH and ML Dustin. (2019). Steering CAR T cells into solid tumors. N Engl J Med 380:289-291.

57. Newick K, O'S Brien, E Moon and SM Albelda. (2017). CAR T cell therapy for solid tumors. Annu Rev Med 68: 139-152.

58. Chen LF, EEW Cohen and JR Grandis. (2010). New strategies in head and neck cancer: understanding resistance to epidermal growth factor receptor inhibitors. Clin Cancer Res 16:2489-2495.

59. Bonner JA, J De Los Santos, HW Waksal, MN Needle, HQ Trummel and KP Raisch. (2002). Epidermal growth factor receptor as a therapeutic target in head and neck cancer. Semin Radiat Oncol 12:11-20.

60. Feng K, Y Guo, H Dai, Y Wang, X Li, H Jia and W Han. (2016). Chimeric antigen receptor-modified T cells for the immunotherapy of patients with EGFR-expressing advanced relapsed/refractory non-small cell lung cancer. Sci China Life Sci 59:468-479.

61. Zimmermann M, A Zouhair, D Azria and M Ozsahin. (2006). The epidermal growth factor receptor (EGFR) in head and neck cancer: its role and treatment implications. Radiat Oncol 1:11.

62. Mittal D, MM Gubin, RD Schreiber and MJ Smyth. (2014). New insights into cancer immunoediting and its three component phases-elimination, equilibrium and escape. Curr Opin Immunol 27:16-25.

63. Wilczynski JR and M Nowak. (2014). In: Interaction of Immune and Cancer Cells. Klink M, ed. Springer, Vienna, pp 143-205.

64. Kim R, M Emi and K Tanabe. (2007). Cancer immunoediting from immune surveillance to immune escape. Immunology 121:1-14.
65. Lacy P and JL Stow. (2011). Cytokine release from innate immune cells: association with diverse membrane trafficking pathways. Blood 118:9-18.

66. Hannafon BN and W-Q Ding. (2015). Cancer stem cells and exosome signaling. Stem Cell Investig 2:11.

67. Jones J. (2019). Glioblastoma single extracellular vesicle analysis profiles: wading into new oceans of tumor data. Neuro Oncol 21:562-564.

68. Lin C-J, E-J Yun, UG Lo, Y-L Tai, S Deng, E Hernandez, A Dang, Y-A Chen, D Saha, et al. (2019). The paracrine induction of prostate cancer progression by caveolin-1. Cell Death Dis 10:834.

69. Vera N, S Acuna-Gallardo, F Grunenwald, A CaceresVerschae, O Realini, R Acuna, A Lladser, SE Illanes and M Varas-Godoy. (2019). Small extracellular vesicles released from ovarian cancer spheroids in response to cisplatin promote the pro-tumorigenic activity of mesenchymal stem cells. Int J Mol Sci 20:E4972.

70. El Andaloussi S, I Mäger, XO Breakefield and MJA Wood. (2013). Extracellular vesicles: biology and emerging therapeutic opportunities. Nat Rev Drug Discov 12:347.

71. Thery C, KW Witwer, E Aikawa, MJ Alcaraz, JD Anderson, R Andriantsitohaina, A Antoniou, T Arab, F Archer, et al. (2018). Minimal information for studies of extracellular vesicles 2018 (MISEV2018): a position statement of the International Society for Extracellular Vesicles and update of the MISEV2014 guidelines. J Extracell Vesicles 7:1535750.

72. Choi DS, DK Kim, YK Kim and YS Gho. (2015). Proteomics of extracellular vesicles: exosomes and ectosomes. Mass Spectrom Rev 34:474-490.

73. Deatherage BL and BT Cookson. (2012). Membrane vesicle release in bacteria, eukaryotes, and archaea: a conserved yet underappreciated aspect of microbial life. Infect Immun 80:1948-1957.

74. Jella K, T Nasti, Z Li, S Malla, Z Buchwald and M Khan. (2018). Exosomes, their biogenesis and role in intercellular communication, tumor microenvironment and cancer immunotherapy. Vaccines 6:69.

75. Datta A, H Kim, M Lal, L McGee, A Johnson, AA Moustafa, JC Jones, D Mondal, M Ferrer and AB AbdelMageed. (2017). Manumycin A suppresses exosome biogenesis and secretion via targeted inhibition of Ras/Raf/ ERK1/2 signaling and hnRNP H1 in castration-resistant prostate cancer cells. Cancer Lett 408:73-81.

76. Siravegna G, S Marsoni, S Siena and A Bardelli. (2017). Integrating liquid biopsies into the management of cancer. Nat Rev Clin Oncol 14:531.

77. Properzi F, M Logozzi and S Fais. (2013). Exosomes: the future of biomarkers in medicine. Biomark Med 7:769778.

78. Bernardi S, C Foroni, C Zanaglio, F Re, N Polverelli, A Turra, E Morello, M Farina, F Cattina, et al. (2019). Feasibility of tumor-derived exosome enrichment in the onco-hematology leukemic model of chronic myeloid leukemia. Int J Mol Med 44:2133-2144.

79. Lin J, J Li, B Huang, J Liu, X Chen, X-M Chen, Y-M Xu, L-F Huang and X-Z Wang. (2015). Exosomes: novel biomarkers for clinical diagnosis. Sci World J 2015:8.

80. Vallabhajosyula P, L Korutla, A Habertheuer, M Yu, S Rostami, C-X Yuan, S Reddy, C Liu, V Korutla, et al. (2017). Tissue-specific exosome biomarkers for noninvasively monitoring immunologic rejection of transplanted tissue. J Clin Invest 127:1375-1391. 
81. Ludwig S, T Floros, M-N Theodoraki, C-S Hong, EK Jackson, S Lang and TL Whiteside. (2017). Suppression of lymphocyte functions by plasma exosomes correlates with disease activity in patients with head and neck cancer. Clin Cancer Res 23:4843-4854.

82. Halvaei S, S Daryani, SZ Eslami, T Samadi, N JafarbeikIravani, TO Bakhshayesh, AK Majidzadeh and R Esmaeili. (2018). Exosomes in cancer liquid biopsy: a focus on breast cancer. Mol Ther Nucleic Acids 10:131-141.

83. Groeneveld A. (2018). Exosome Diagnostics Expands National Sales Team after Blockbuster Quarter with its Flagship Diagnostic, ExoDx Prostate ${ }^{\circledR}$ (IntelliScore) (EPI) Test. Press Release. https://epi.exosomedx.com/newsevents/press-releases/ accessed May 8, 2018.

84. Elena Castellanos-Rizaldos, Dominik G. Grimm, Vasisht Tadigotla, James Hurley, John Healy, Patricia L. Neal, Mia Sher, Raajdeep Venkatesan, Chris Karlovich, Mitch Raponi, Anne Krug, Mikkel Noerholm, Jihane Tannous, Bakhos A. Tannous, Luis E. Raez and Johan K. Skog. (2018). Exosome-Based Detection of EGFR T790M in Plasma from Non-Small Cell Lung Cancer Patients. Clin Cancer Res June 15:2944-2950.

85. Maccalli C, KI Rasul, M Elawad and S Ferrone. (2018). The role of cancer stem cells in the modulation of antitumor immune responses, Seminars in Cancer Biology, 53:189-200.

86. Whiteside TL. (2016). In: Advances in Clinical Chemistry. Makowski GS, ed. Elsevier, 74:pp 103-141.

87. Yang C and PD Robbins. (2011). The roles of tumorderived exosomes in cancer pathogenesis. Clin Dev Immunol 2011:11.

88. Plebanek MP, NL Angeloni, E Vinokour, J Li, A Henkin, D Martinez-Marin, S Filleur, R Bhowmick, J Henkin, et al. (2017). Pre-metastatic cancer exosomes induce immune surveillance by patrolling monocytes at the metastatic niche. Nat Commun 8:1319.

89. Maia J, S Caja, MC Strano Moraes, N Couto and B CostaSilva. (2018). Exosome-based cell-cell communication in the tumor microenvironment. Front Cell Dev Biol 6:18.

90. Morelli AE, AT Larregina, WJ Shufesky, MLG Sullivan, DB Stolz, GD Papworth, AF Zahorchak, AJ Logar, Z Wang, et al. (2004). Endocytosis, intracellular sorting, and processing of exosomes by dendritic cells. Blood 104: 3257-3266.

91. Nanbo A, E Kawanishi, R Yoshida and H Yoshiyama. (2013). Exosomes derived from Epstein-Barr virusinfected cells are internalized via caveola-dependent endocytosis and promote phenotypic modulation in target cells. J Virol 87:10334-10347.

92. Whiteside TL. (2016). Exosomes and tumor-mediated immune suppression. J Clin Invest 126:1216-1223.

93. Onishi H, J Wada, H Suzuki, A Yamasaki, S Nagai, T Morisaki and M Katano. (2010). Effect of TGF- $\beta 1$ expressed on tumor-derived exosomes on survival and function of regulatory T cells. J Clin Oncol 28:2567-2574.

94. Poggio M, T Hu, CC Pai, B Chu, CD Belair, A Chang, E Montabana, UE Lang, Q Fu, L Fong and R Blelloch. (2019). Suppression of exosomal PD-L1 induces systemic anti-tumor immunity and memory. Cell 177:414427.e413.

95. Clayton A, S Al-Taei, J Webber, MD Mason and Z Tabi. (2011). Cancer exosomes express CD39 and CD73, which suppress T cells through adenosine production. J Immunol 187:676-683.
96. Schuler P, Z Saze, CS Hong, L Muller, D Gillespie, D Cheng, M Harasymczuk, M Mandapathil, S Lang and E Jackson. (2014). Human CD 4+ CD 39+ regulatory T cells produce adenosine upon co-expression of surface CD 73 or contact with CD 73+ exosomes or CD 73+ cells. Clin Exp Immunol 177:531-543.

97. Vijayan D, A Young, MW Teng and MJ Smyth. (2017). Targeting immunosuppressive adenosine in cancer. Nat Rev Cancer 17:709.

98. Ohta A. (2016). A metabolic immune checkpoint: adenosine in tumor microenvironment. Front Immunol 7:109.

99. Muller-Haegele S, L Muller and TL Whiteside. (2014). Immunoregulatory activity of adenosine and its role in human cancer progression. Expert Rev Clin Immunol 10: 897-914.

100. Leone RD and LA Emens. (2018). Targeting adenosine for cancer immunotherapy. J Immunother Cancer 6:57.

101. Wieckowski EU, C Visus, M Szajnik, MJ Szczepanski, WJ Storkus and TL Whiteside. (2009). Tumor-derived microvesicles promote regulatory $\mathrm{T}$ cell expansion and induce apoptosis in tumor-reactive activated CD8+ T lymphocytes. J Immunol 183:3720-3730.

102. Muller L, P Simms, C-S Hong, MI Nishimura, EK Jackson, SC Watkins and TL Whiteside. (2017). Human tumor-derived exosomes (TEX) regulate Treg functions via cell surface signaling rather than uptake mechanisms. Oncoimmunology 6:e1261243.

103. Kim JW, E Wieckowski, DD Taylor, TE Reichert, S Watkins and TL Whiteside. (2005). Fas ligand-positive membranous vesicles isolated from sera of patients with oral cancer induce apoptosis of activated T lymphocytes. Clin Cancer Res 11:1010-1020.

104. Theodoraki M, S Yerneni, T Hoffmann, W Gooding and T Whiteside. (2018). Clinical significance of PD-L1+ exosomes in plasma of head and neck cancer patients. Clin Cancer Res 24:896.

105. Galdiero MR, E Bonavita, I Barajon, C Garlanda, A Mantovani and S Jaillon. (2013). Tumor associated macrophages and neutrophils in cancer. Immunobiology 218: 1402-1410.

106. Curry JM, J Sprandio, D Cognetti, A Luginbuhl, V Bar-ad, E Pribitkin and M Tuluc. (2014). Tumor microenvironment in head and neck squamous cell carcinoma. Semin Oncol 41:217-234.

107. Hsieh C-H, S-K Tai and M-H Yang. (2018). Snailoverexpressing cancer cells promote M2-like polarization of tumor-associated macrophages by delivering MiR-21abundant exosomes. Neoplasia 20:775-788.

108. Sakaguchi S, T Yamaguchi, T Nomura and M Ono. (2008). Regulatory $\mathrm{T}$ cells and immune tolerance. Cell 133:775-787.

109. Josefowicz SZ, L-F Lu and AY Rudensky. (2012). Regulatory T cells: mechanisms of differentiation and function. Annu Rev Immunol 30:531-564.

110. Brusko TM, AL Putnam and JA Bluestone. (2008). Human regulatory $\mathrm{T}$ cells: role in autoimmune disease and therapeutic opportunities. Immunol Rev 223:371-390.

111. Park SS, E Moisseiev, G Bauer, JD Anderson, MB Grant, A Zam, RJ Zawadzki, JS Werner and JA Nolta. (2017). Advances in bone marrow stem cell therapy for retinal dysfunction. Prog Retin Eye Res 56:148-165.

112. Pollock K, H Dahlenburg, H Nelson, KD Fink, W Cary, K Hendrix, G Annett, A Torrest, P Deng, et al. (2016). Human mesenchymal stem cells genetically engineered to 
overexpress brain-derived neurotrophic factor improve outcomes in Huntington's disease mouse models. Mol Ther 24:965-977.

113. Velichko S, X Zhou, L Zhu, JD Anderson, R Wu and Y Chen. (2016). A novel nuclear function for the interleukin17 signaling adaptor protein Act1. PLoS One 11:e0163323.

114. Beyer M and JL Schultze. (2006). Regulatory T cells in cancer. Blood 108:804-811.

115. Facciabene A, GT Motz and G Coukos. (2012). Tregulatory cells: key players in tumor immune escape and angiogenesis. Cancer Res 72:2162-2171.

116. Ebinuma H, N Nakamoto, Y Li, DA Price, E Gostick, BL Levine, J Tobias, WW Kwok and K-M Chang. (2008). Identification and in vitro expansion of functional antigenspecific $\mathrm{CD} 25+$ FoxP3+ regulatory $\mathrm{T}$ cells in hepatitis $\mathrm{C}$ virus infection. J Virol 82:5043-5053.

117. Létourneau S, C Krieg, G Pantaleo and O Boyman. (2009). IL-2- and CD25-dependent immunoregulatory mechanisms in the homeostasis of T-cell subsets. $\mathrm{J}$ Allergy Clin Immunol 123:758-762.

118. Schaefer C, G Kim, A Albers, K Hoermann, E Myers and $\mathrm{T}$ Whiteside. (2005). Characteristics of CD4+ CD25+ regulatory $\mathrm{T}$ cells in the peripheral circulation of patients with head and neck cancer. Br J Cancer 92:913.

119. Mrizak D, N Martin, C Barjon, A-S Jimenez-Pailhes, R Mustapha, T Niki, J Guigay, V Pancré, Y de Launoit and P Busson. (2015). Effect of nasopharyngeal carcinomaderived exosomes on human regulatory $\mathrm{T}$ cells. J Natl Cancer Inst 107:363-372.

120. Szajnik M, M Czystowska, M Szczepanski, M Mandapathil and T Whiteside. (2010). Tumor-derived microvesicles induce, expand and up-regulate biological activities of human regulatory T cells (Treg). PLoS One 5: e11469.

121. Muller L, M Mitsuhashi, P Simms, WE Gooding and TL Whiteside. (2016). Tumor-derived exosomes regulate expression of immune function-related genes in human $\mathrm{T}$ cell subsets. Sci Rep 6:20254.

122. Strauss L, C Bergmann, M Szczepanski, W Gooding, JT Johnson and TL Whiteside. (2007). A unique subset of CD4+ CD25highFoxp3+ T cells secreting interleukin-10 and transforming growth factor- $\beta 1$ mediates suppression in the tumor microenvironment. Clin Cancer Res 13: 4345-4354.

123. Cao X, SF Cai, TA Fehniger, J Song, LI Collins, DR Piwnica-Worms and TJ Ley. (2007). Granzyme B and perforin are important for regulatory $\mathrm{T}$ cell-mediated suppression of tumor clearance. Immunity 27:635-646.

124. Gondek DC, V DeVries, EC Nowak, L-F Lu, KA Bennett, ZA Scott and RJ Noelle. (2008). Transplantation survival is maintained by granzyme $\mathrm{B}+$ regulatory cells and adaptive regulatory T cells. J Immunol 181:4752-4760.

125. Visvader JE and GJ Lindeman. (2008). Cancer stem cells in solid tumours: accumulating evidence and unresolved questions. Nat Rev Cancer 8:755.

126. Miao Y, H Yang, J Levorse, S Yuan, L Polak, M Sribour, B Singh, MD Rosenblum and E Fuchs. (2019). Adaptive immune resistance emerges from tumor-initiating stem cells. Cell 177:1172-1186.e1114.

127. Batlle E and H Clevers. (2017). Cancer stem cells revisited. Nat Med 23:1124.

128. Al-Hajj M, MS Wicha, A Benito-Hernandez, SJ Morrison and MF Clarke. (2003). Prospective identification of tu- morigenic breast cancer cells. Proc Natl Acad Sci U S A 100:3983-3988.

129. Prince M, R Sivanandan, A Kaczorowski, G Wolf, M Kaplan, P Dalerba, I Weissman, M Clarke and L Ailles. (2007). Identification of a subpopulation of cells with cancer stem cell properties in head and neck squamous cell carcinoma. Proc Natl Acad Sci U S A 104:973-978.

130. Mitra A, L Mishra and S Li. (2015). EMT, CTCs and CSCs in tumor relapse and drug-resistance. Oncotarget 6: 10697-10711.

131. Peitzsch C, A Tyutyunnykova, K Pantel and A Dubrovska. (2017). Cancer stem cells: the root of tumor recurrence and metastases. Semin Cancer Biol 44:10-24.

132. Chang JC. (2016). Cancer stem cells: role in tumor growth, recurrence, metastasis, and treatment resistance. Medicine 95:S20-S25.

133. Klonisch T, E Wiechec, S Hombach-Klonisch, SR Ande, S Wesselborg, K Schulze-Osthoff and M Los. (2008). Cancer stem cell markers in common cancers-therapeutic implications. Trends Mol Med 14:450-460.

134. Davis SJ, V Divi, JH Owen, CR Bradford, TE Carey, S Papagerakis and MEP Prince. (2010). Metastatic potential of cancer stem cells in head and neck squamous cell carcinoma metastatic potential of cancer stem cells in HNSCC. JAMA Otolaryngol Head Neck Surg 136:12601266.

135. Shrivastava S, R Steele, M Sowadski, SE Crawford, M Varvares and RB Ray. (2015). Identification of molecular signature of head and neck cancer stem-like cells. Sci Rep 5:7819.

136. Okamoto A, K Chikamatsu, K Sakakura, K Hatsushika, G Takahashi and K Masuyama. (2009). Expansion and characterization of cancer stem-like cells in squamous cell carcinoma of the head and neck. Oral Oncol 45:633-639.

137. Chen Y-C, Y-W Chen, H-S Hsu, L-M Tseng, P-I Huang, K-H Lu, D-T Chen, L-K Tai, M-C Yung and S-C Chang. (2009). Aldehyde dehydrogenase 1 is a putative marker for cancer stem cells in head and neck squamous cancer. Biochem Biophys Res Commun 385:307-313.

138. Chikamatsu K, G Takahashi, K Sakakura, S Ferrone and $\mathrm{K}$ Masuyama. (2011). Immunoregulatory properties of CD44+ cancer stem-like cells in squamous cell carcinoma of the head and neck. Head Neck 33:208-215.

139. Qian X, C Ma, X Nie, J Lu, M Lenarz, AM Kaufmann and AE Albers. (2015). Biology and immunology of cancer stem (-like) cells in head and neck cancer. Crit Rev Oncol Hematol 95:337-345.

140. Sultan M, KM Coyle, D Vidovic, ML Thomas, S Gujar and P Marcato. (2016). Hide-and-seek: the interplay between cancer stem cells and the immune system. Carcinogenesis 38:107-118.

141. Ying J, M Tsujii, J Kondo, Y Hayashi, M Kato, T Akasaka, T Inoue, E Shiraishi, T Inoue, et al. (2015). The effectiveness of an anti-human IL-6 receptor monoclonal antibody combined with chemotherapy to target colon cancer stem-like cells. Int J Oncol 46:1551-1559.

142. Wei H. (2019). Interleukin 6 signaling maintains the stemlike properties of bladder cancer stem cells. Transl Cancer Res 8:557-566.

143. Haderk F, R Schulz, M Iskar, LL Cid, T Worst, KV Willmund, A Schulz, U Warnken, J Seiler, et al. (2017). Tumor-derived exosomes modulate PD-L1 expression in monocytes. Sci Immunol 2:eaah5509. 
144. Zomer A, C Maynard, FJ Verweij, A Kamermans, R Schäfer, E Beerling, RM Schiffelers, E de Wit, J Berenguer, et al. (2015). In vivo imaging reveals extracellular vesicle-mediated phenocopying of metastatic behavior. Cell 161:1046-1057.

145. Skog J, T Würdinger, S van Rijn, DH Meijer, L Gainche, WT Curry, Jr., BS Carter, AM Krichevsky and XO Breakefield. (2008). Glioblastoma microvesicles transport RNA and proteins that promote tumour growth and provide diagnostic biomarkers. Nat Cell Biol 10:1470.

146. Alzahrani FA, MA El-Magd, A Abdelfattah-Hassan, AA Saleh, IM Saadeldin, ES El-Shetry, AA Badawy and S Alkarim. (2018). Potential effect of exosomes derived from cancer stem cells and MSCs on progression of DENinduced HCC in rats. Stem Cells Int 2018:8058979.

147. Eguchi T, C Sogawa, Y Okusha, K Uchibe, R Iinuma, K Ono, K Nakano, J Murakami, M Itoh, et al. (2018). Organoids with cancer stem cell-like properties secrete exosomes and HSP90 in a 3D nanoenvironment. PLoS One 13:e0191109.

148. Grange C, M Tapparo, F Collino, L Vitillo, C Damasco, MC Deregibus, C Tetta, B Bussolati and G Camussi. (2011). Microvesicles released from human renal cancer stem cells stimulate angiogenesis and formation of lung premetastatic niche. Cancer Res 71:5346-5356.

149. Anderson JD, HJ Johansson, CS Graham, M Vesterlund, MT Pham, CS Bramlett, EN Montgomery, MS Mellema, RL Bardini, et al. (2016). Comprehensive proteomic analysis of mesenchymal stem cell exosomes reveals modulation of angiogenesis via nuclear factor-kappaB signaling. Stem Cells 34:601-613.

150. Moisseiev E, JD Anderson, S Oltjen, M Goswami, RJ Zawadzki, JA Nolta and SS Park. (2017). Protective effect of intravitreal administration of exosomes derived from mesenchymal stem cells on retinal ischemia. Curr Eye Res 42:1358-1367.

151. Showalter MR, B Wancewicz, O Fiehn, JA Archard, S Clayton, J Wagner, P Deng, J Halmai, KD Fink, et al. (2019). Primed mesenchymal stem cells package exosomes with metabolites associated with immunomodulation. Biochem Biophys Res Commun 512:729-735.

152. Yuan O, C Lin, J Wagner, JA Archard, P Deng, J Halmai, G Bauer, KD Fink, B Fury, et al. (2019). Exosomes derived from human primed mesenchymal stem cells induce mitosis and potentiate growth factor secretion. Stem Cells Dev 28:398-409.

153. Becker A, BK Thakur, JM Weiss, HS Kim, H Peinado and D Lyden. (2016). Extracellular vesicles in cancer: cell-to-cell mediators of metastasis. Cancer Cell 30: 836-848.

$$
\begin{array}{r}
\text { Address correspondence to: } \\
\text { Dr. Johnathon D. Anderson } \\
\text { Department of Otolaryngology } \\
\text { University of California Davis Medical Center } \\
2921 \text { Stockton Boulevard, Room } 1300 \\
\text { Sacramento, CA } 95817 \\
\text { E-mail: joanderson@ucdavis.edu }
\end{array}
$$

Received for publication September 9, 2019

Accepted after revision December 19, 2019

Prepublished on Liebert Instant Online December 20, 2019 